\title{
Design and Characterization of a Novel Rotating Corrugated Drum Reactor for Wastewater Treatment
}

\author{
Sarah M. Meunier, Joanne Gamage, Zdravko Duvnjak, and Zisheng Zhang \\ Department of Chemical and Biological Engineering, University of Ottawa, Ottawa, ON, Canada K1N 6N5 \\ Correspondence should be addressed to Zisheng Zhang, jason.zhang@uottawa.ca
}

Received 15 August 2010; Revised 21 November 2010; Accepted 6 December 2010

Academic Editor: Vincenzo Augugliaro

Copyright (C 2010 Sarah M. Meunier et al. This is an open access article distributed under the Creative Commons Attribution License, which permits unrestricted use, distribution, and reproduction in any medium, provided the original work is properly cited.

\begin{abstract}
A novel photoreactor system consisting of a $\mathrm{TiO}_{2}$-coated corrugated drum and a UV light source is experimentally characterized for the treatment of phenol-polluted wastewaters. The design incorporates periodic illumination and increased agitation through the introduction of rotation. The effects ofrent degrees and flat fins to increase surface area, varying rotational speed, initial pollutant concentration, and illumination intensities were studied. The corrugated and finned drums did not exhibit a critical rotational speed, indicating that there is excellent mass transfer in the system. A Langmuir-Hinshelwood kinetic analysis was applied to the degradation, and an average adsorption coefficient of $K=0.120 \mathrm{~L} / \mathrm{mg}$ was observed. The overall reaction rate increased with increasing surface area from $0.046 \mathrm{mg} / \mathrm{L} / \mathrm{min}$ for the annular drum to $0.16 \mathrm{mg} / \mathrm{L} / \mathrm{min}$ for the 40 -fin drum. The apparent photonic efficiency was found to increase with increasing surface area at a faster rate for the corrugations than for the fin additions. The energy efficiency (EE/O) found for the drums varied from $380-550 \mathrm{kWh} / \mathrm{m}^{3}$, which is up to $490 \%$ more energy-efficient than the annular drum.
\end{abstract}

\section{Introduction}

1.1. Photocatalysis. Photocatalytic degradation of persistent organic contaminants using oxide semiconductor catalysts has been shown to be an effective alternative for the purification of contaminated air and water [1]. $\mathrm{TiO}_{2}$ is currently the most widely used photocatalyst due to its high photocatalytic activity, stability, and nontoxicity [2,3]. Vinod and Anirudhan provide an extensive list of the many organic and inorganic pollutants that can be degraded using photocatalysis [4].

1.2. Photoreactor Design Considerations. Some challenges involved in the development of a photocatalytic reactor are optimizing light distribution, providing high surface areas for catalyst per unit reactor volume and providing sufficient mixing inside the reactor [5]. Superior catalysts, more efficient light sources, or novel photoreactors are needed in order for photocatalysis to become acceptably cost-effective and gain wider industrial application [6]. A powerful and energy-efficient photocatalytic reactor should have, ideally:
(1) a large catalyst surface area per unit reactor volume, (2) the capability to continuously or periodically deliver artificial and/or solar radiation to a large catalyst surface, (3) sufficient mass transfer capacity between the liquid bulk and the reaction sites, and (4) the ability for the catalyst to recapture photons reflected from the catalyst surface [7].

Many novel photoreactor designs and configurations have been developed and studied, including the annular photoreactor [8-11], the packed-bed photoreactor [12], the photocatalytic Taylor vortex reactor [13], the $\mathrm{TiO}_{2}$ fluidized bed reactor [14], the $\mathrm{TiO}_{2}$-coated fiber optic cable reactor [15-18], the falling film reactor [19], the thin-film-fixedbed sloping plate reactor [20], the swirl-flow reactor [21], the integrated membrane reactor [22], the monolith reactor [23], and the thin-film reactor, to name a few of the numerous designs investigated. Photocatalytic processes and discussion of novel photoreactors are presented in numerous reviews [24-29], including an excellent paper by Braham and Harris which summarizes the reactor designs developed which utilize solar illumination [30]. 
1.3. Previous Studies on Corrugated and Rotating Photoreactors. In studies of a continuous corrugated plate reactor system using $30 \mathrm{mg} / \mathrm{L}$ of 4-chlorophenol [6], it was found that the corrugated plate reactors were able to degrade the pollutant up to $150 \%$ faster than flat plate reactors with similar dimensions, and that the degradation rates found were comparable to a $1 \mathrm{~g} / \mathrm{L}$ slurry reactor. The electrical energy was estimated to be near that of the slurry system, and the mass transfer rates were found to be $400 \%-600 \%$ higher than flat plate reactors. It was found that the angle of corrugation significantly affected the reactor performance, and decreasing the angle of corrugation increased the efficiency of the system due to higher mass transfer capabilities and larger illuminated catalyst areas. Additionally, it was shown by rigorous modelling that the corrugated plates with smaller angles could capture a larger fraction of the reflected photons, thus enhancing energy efficiency up to $50 \%$ more than flat-plate reactors by more effectively using the incident illumination $[31,32]$. However, it was also found that the smaller angles led to less uniform reactant concentrations on catalyst surfaces and could not eliminate the mass-transfer limitations on the degradation rate that were observed for both corrugated and flat plates [32].

The introduction of rotation to photocatalytic reactors has been explored [33-36] in order to enhance the mass transfer rates in the system by continuously bringing pollutant to the surface of the reactor, as well as increasing photoefficiency by employing controlled periodic illumination, which has been shown to reduce the buildup of redox intermediates and reduce the rate of undesirable sidereactions [37].

Zhang et al. explored the use of a rotating disc reactor (RDR) in which photocatalyst is immobilized on discs which are arranged on a horizontal spool, forming "teeth" [7]. The effects of film thickness, angle of teeth, and radiation intensity were studied for the degradation of 4-chlorophenol, and the results were compared to a rotating, smooth drum. The rotational speed was found to influence the film thickness, and a critical rotational speed between 5 and $20 \mathrm{rpm}$ was determined, below which the water film formed on the drum was too thin to provide the pollutant to the photocatalytic surface at a rate equal to or faster than the degradation potential of the photocatalyst. A small angle between the teeth was determined to be more optimal, and it was found, using experimental data and the LASREA model [38], that the disc configuration had a larger illuminated area than a rotating drum, but that the photon flow rate in both cases was similar, and the photonic efficiency of the disc reactor was nearly twice that of the drum. A conclusion was reached that, using a fixed light source, to distribute limited photons onto more photocatalyst area is an effective principle for engineering design.

The degradation of a $22 \mathrm{ppm}$ solution of phenol using a $\mathrm{Pt}-\mathrm{TiO}_{2}$ catalyst on a rotating drum reactor was reported using UV and solar illumination sources [36]. Phenol was completely mineralized within $100 \mathrm{~min}$ in both cases, and initial degradation rates of $1.635 \mathrm{mg} / \mathrm{m}^{2} \cdot \mathrm{min}$ and $4.88 \mathrm{mg} / \mathrm{m}^{2} \cdot \mathrm{min}$ were realized for the solar and UV systems, respectively, using the Langmuir-Hinshelwood kinetic model. The degradation rate was found to increase with rotation speed, and a critical speed of $25 \mathrm{rpm}$ was determined. The photonic efficiency using the UV lights $(2 \times 6 \mathrm{~W}$ mercury lights at $\lambda=253.7 \mathrm{~nm}$ ) was much higher than that for solar light.

A rotating disk reactor was also developed by Dionysiou et al. $[37,39,40]$. The reactor was validated in continuous mode for the degradation of phenol, chlorinated phenols, and lindane as model pollutants [40]. It was found that above a disc angular velocity of $6 \mathrm{rpm}$, there was no significant improvement in the reaction rate, indicating a reduction of mass transfer limitation above this speed. LangmuirHinshelwood kinetics were used to describe the system as well, and the illumination profile was modelled.

Hamill et al. [34] studied a rotating disk photocatalytic reactor comprised of four glass rotating disks immobilized with titanium dioxide and UV lamps mounted between the disks for the degradation of chlorinated VOCs and other organics. This design showed degradation rates approaching a slurry reactor, and a stepwise increase in degradation rate was found for rotational speeds from 0 to $136 \mathrm{rpm}$ due to changing mass transfer properties in the system with changing rotational speeds. It was found that the mass transfer processes strongly contribute to the reaction rate in this system.

1.4. Development of Corrugated Drum Rotating Reactor. In this work, a novel photocatalytic reactor is proposed and experimentally validated. The reactor system consists of a $\mathrm{TiO}_{2}$-coated rotating drum with a corrugated surface that is partially immersed in an aqueous solution of model wastewater using phenol as the model pollutant and an UV light source to illuminate the reactor from above.

A corrugated surface was chosen to increase the available surface area for catalyst immobilization, to exploit the potential to recapture reflected light, and to improve the mass transfer of polluted water to reaction sites. Additionally, the rotation also introduces an effective controlled periodic illumination on the drum, as only half is illuminated at a time. Agitation is introduced in the system through the use of corrugations, and this is beneficial for maintaining a wellmixed situation and adding dissolved oxygen to the reaction medium. Since the $\mathrm{TiO}_{2}$ film is hydrophilic, the water can easily be drawn up along the surface by the drum rotating due to viscous shear, resulting in a continuous water film being formed on the surface [36].

Several drums of different corrugation profiles were studies, and the effect of added surface area was explored. Additionally, the rotational speed, initial pollutant concentration, and illumination intensities were studied. This study is intended to facilitate the design of photoreactor systems by providing a unique drum configuration which maximizes the mass transfer in the system and promotes the efficient degradation of wastewaters.

\section{Materials and Experimental Methods}

2.1. Photoreactor System. The reactor apparatus without the illumination source is shown in Figure 1. The drums, 


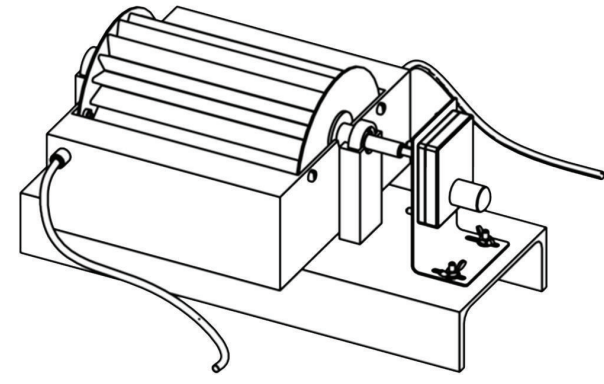

Figure 1: Photoreactor experimental apparatus.

light support, and reactor were all constructed in-house of stainless steel. The double-walled reactor tank circulates cooling water to maintain the process water temperature at $10^{\circ} \mathrm{C}$. The illumination source consists of three $40 \mathrm{~W}$ mercury reflector black-lights (TLK 40 W/10 R UVA, Microlites Scientific, Ontario, Canada), which emit light with an average wavelength of $353 \mathrm{~nm}$. The catalyst coated drums are partially immersed in the polluted water and rotated with a 12 V DC gear-motor (Acklands-Grainger, Ontario, Canada). The rotational speed is controlled with a variable DC power supply (EPSCO Incorporated, Illinois, US).

Each drum was constructed from a stainless steel cylinder $6.4 \mathrm{~cm}$ in diameter and $20.3 \mathrm{~cm}$ in length with $2 \mathrm{~cm}$ high corrugations. The seven drum configurations are (a) no corrugations, (b) sixteen fins, (c) twenty-eight fins, (d) forty fins, (e) thirty degree angle, (f) twenty degree angle, and (g) ten degree angle (Figure 2). The nominal surface area available for catalyst immobilization of each drum is shown in Table 1.

2.2. Catalyst Immobilization. A $180 \mathrm{~g} / \mathrm{L}$ slurry of titanium dioxide (Aeroxide P25, Degussa Corporation, New Jersey, US) in 25\% aqueous methanol (Optima 99.9\% methanol, Fisher Chemicals, Ontario, Canada) was prepared to immobilize the titanium dioxide catalyst on the stainless steel drums. The drums were sanitized with detergent and distilled water, and heated to $200^{\circ} \mathrm{C}$ for two hours. Once cool, the catalyst slurry was applied to the drums and heated to $275^{\circ} \mathrm{C}$ for five hours to immobilize the catalyst.

2.3. Experimental Procedure. Before completing the experimental runs, control runs were completed to ensure that no phenol degradation occurred unless the catalyst, illumination, and rotation were all present. In addition, repetition runs were periodically completed to ensure the reproducibility of the experimental data. In preparation for each experimental run, the reactor drum and tank were rinsed with distilled water to remove any detached catalyst, remaining pollutant, and reaction intermediates. The cooling water circulation and the drum rotation were initiated, and, when the system stabilized, $1.25 \mathrm{~L}$ of phenol (99\%, Sigma-Aldrich Inc., Missouri, US) in an aqueous solution was added to the reactor tank and the illumination was turned on. Samples of the reaction media were taken approximately every thirty minutes and analyzed with a

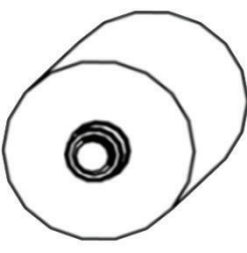

(a) No corrugations

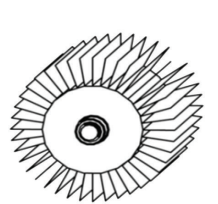

(d) 40 Fins

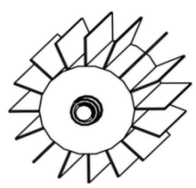

(b) 16 Fins

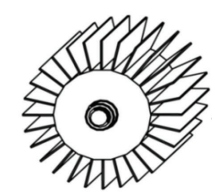

(c) 28 Fins

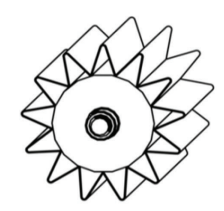

(e) $30^{\circ}$ Angle

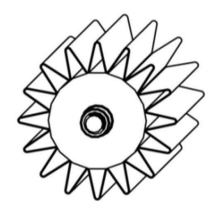

(f) $20^{\circ}$ Angle

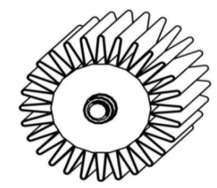

(g) $10^{\circ}$ Angle

FIgURE 2: Reactor drum configurations.

GENYSYS 10-UV spectrophotometer (Geneq Inc., Quebec, Canada) at $209 \mathrm{~nm}$ which is the highest absorbance peak for phenol. The water temperature and the rotational speed of the reactor drum were monitored regularly to ensure that they remained constant throughout the experimental run, which lasted approximately six hours. To determine the presence of reaction intermediates, some runs were tested with Waters HPLC system as well as the spectrophotometer. In this analysis, $49.575 \%$ HPLC grade acetonitrile, 50\% deionized distilled water, and $0.425 \%$ phosphoric acid buffer were used as the mobile phase with $5 \mu \mathrm{L}$ injections and absorbance detection at $210 \mathrm{~nm}$. The error associated to the experimental analysis and procedure was the error associated to the spectrophotometer analysis, calculation of the exact rotational speed, inherent experimental error, and so forth, and was quantified by conducting duplicate and triplicate runs. The error was found to be similar in all cases and was approximately $1 \%$.

\section{Results and Discussion}

3.1. Effect of Corrugation Profile. The effects of drum configuration and corrugation profile were studied by performing the degradation of a phenol solution and comparing the initial reaction rate $(\mathrm{C} / \mathrm{Co} / \mathrm{min})$. The initial degradation rate at four different rotational speeds for each of the seven drums is shown in Figure 3.

Although there is some scatter in the data, it can be seen that the initial rate of degradation generally increases with increasing surface area. There is also a significant difference in initial rates between the annular reactor (no corrugations) and the reactors with fins and corrugations, so the addition of the fins and corrugations greatly improves 
TABLE 1: Nominal surface area for each drum configuration.

\begin{tabular}{lc}
\hline Drum configuration & Surface area $\left(\mathrm{cm}^{2}\right)$ \\
\hline No corrugations & 400 \\
16 Fins & 1700 \\
28 Fins & 2700 \\
40 Fins & 3700 \\
$30^{\circ}$ Angle & 1200 \\
$20^{\circ}$ Angle & 1400 \\
$10^{\circ}$ Angle & 2400 \\
\hline
\end{tabular}

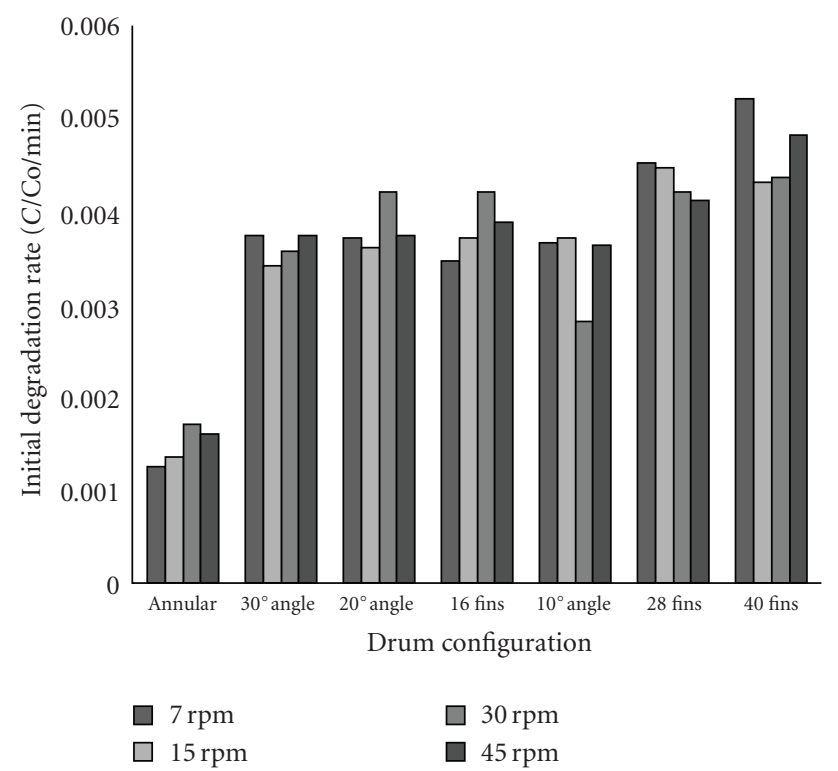

FIgURE 3: Effect of drum configuration and surface area on initial degradation rate.

the performance of the reactor. There is an increase of approximately $200 \%$ between the reactor with the lowest degradation rate (annular) and the highest (40 fins). This increase is due to the larger surface area available for catalyst immobilization, and consequently, a greater number of reaction sites. A better use of incident photons through reflection and recapture by the corrugated and finned drums is also indicated to by their photonic efficiency, as discussed in a subsequent section. This trend is consistent with the literature on corrugated plates [31].

The increase in degradation rate realized is not proportional to the increased surface area, as the normalized perunit-area degradation rates show in Figure 4. It can be seen that the degradation rate per unit surface area decreases with increasing surface area. This is due to the decreased input illumination intensity per unit area at the higher reactor surface areas. However, the final percent degraded using the corrugations and fins, as presented in Figure 5 (for $15 \mathrm{rpm}$ and Co $=15 \mathrm{ppm}$ ), is very similar and varies by a maximum of $6 \%$. A similar result was obtained from the other trials performed. Therefore, although the initial rates decrease with increasing surface area, the overall degradation

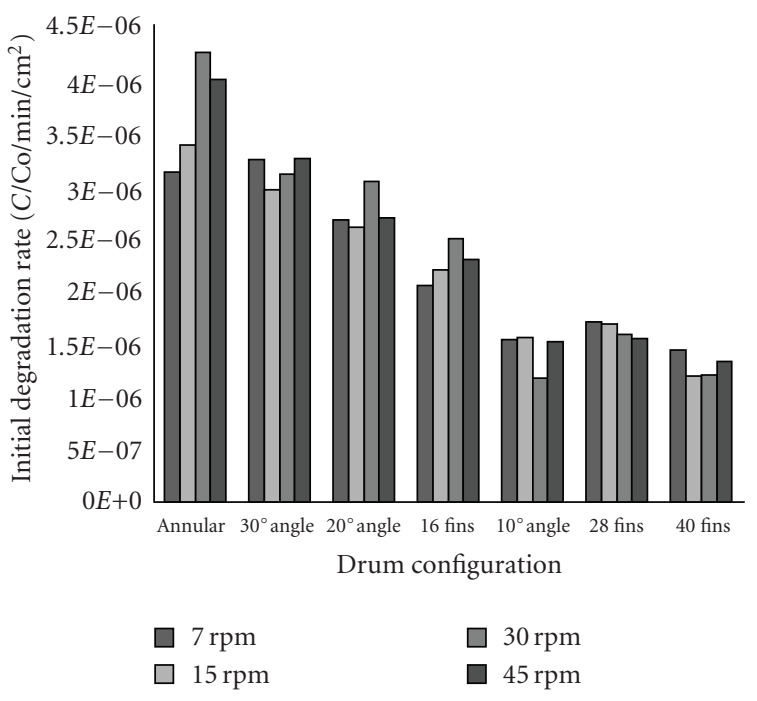

FIgURE 4: Initial degradation rate per unit surface area for the various drum configurations.

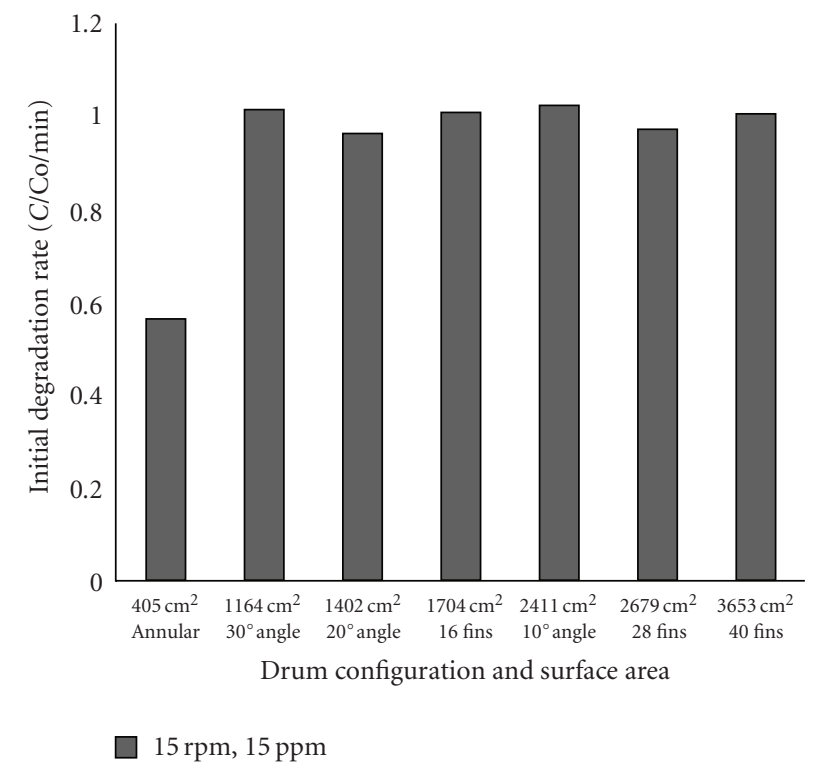

FIGURE 5: Comparison of percent degradation for all drums at trial with $\mathrm{Co}=15 \mathrm{ppm}, 15 \mathrm{rpm}$.

achievable is similar in all the cases of corrugations and fins. The addition of this surface area therefore improves the performance of the reactor when compared to the annular reactor.

3.2. Effect of Dissolved Oxygen. In the degradation of organic compounds, the oxygen plays a large role in the capture of excited electrons, so the rate of oxygen mass transfer must be sufficient to facilitate the degradation at an acceptable rate. In the rotating drum reactors studied, the oxygen is continuously provided from the atmosphere since the housing is open on the top. The oxygen in the atmosphere must penetrate through the water film to reach the photocatalyst 
at the reactor surface, and the flux of oxygen diffusing in the water film can be described according to Fick's first law

$$
N_{0_{2}}=-D \frac{d C_{0_{2}}}{d R} .
$$

Considering an extreme situation where the oxygen at the water surface of the air-water interface is saturated (diffusion coefficient at $10^{\circ} \mathrm{C}=1.54 \times 10^{-5}$ [38]) and completely consumed at the surface of the photocatalyst, the diffusion flux can be estimated using (1) as $\mathrm{N}_{\mathrm{O}_{2}}>6.57 \times 10^{-5} \mathrm{mg} / \mathrm{cm}^{2} \cdot \mathrm{s}$ when the film thickness is less than $26 \mu \mathrm{m}$. The film thickness was estimated using the tissue absorption method developed and validated by Zhang et al. [7] and the annular drum at the maximum rotational speed used in the current studies. The obtained value is in good agreement with the values reported from Zhang et al. [7, 36] for a drum of similar diameter and at a similar rotational speed. The film thickness on the corrugated and finned drums could not be calculated directly due to the formation of bubbles on the surface of these reactors, but it was assumed that the measurement from the annular reactor would represent the upper limit of the film thickness obtainable in this experiment.

The stoichiometric amount of oxygen to mineralize $1.25 \mathrm{~mL}$ of $40 \mathrm{ppm}$ phenol in 6 hours (upper limit of concentration and experimental time in this study) is $4.63 \times$ $10^{-6} \mathrm{mg} / \mathrm{cm}^{2} \cdot \mathrm{s}$, which is much smaller than the available flux. Consequently, the mass transfer and supply of oxygen is not a rate-limiting factor in the photocatalytic process, and it does not need to be included in the kinetic analysis. This also implies that the water does not need to be aerated for this reactor system, which provides an energy-saving benefit in practical operation [36].

3.3. Effect of Rotational Speed. The rotational speed affects the water film thickness formed on the surface of the drum and the mass transfer of the pollutant to the surface of the photocatalyst. The effect of varying the rotational speed from 0 to $45 \mathrm{rpm}$ on the initial degradation rate is given in Figures 6 and 7 for the annular, corrugated, and finned drums, respectively, at an initial concentration of $20 \mathrm{ppm}$.

From the data, there is no correlation that can be confirmed between the rotational speed and the initial degradation rate for the corrugated and finned drums; however, a critical rotational speed between 15 and $30 \mathrm{rpm}$ is observed for the annular drum. This value is in good agreement with the literature for photocatalytic rotating cylinders; in Zhang et al. the critical value was found to be between 5 and $20 \mathrm{rpm}$ for similar geometry (4-chlorophenol) [7], and $25 \mathrm{rpm}$ for the annular employing a $\mathrm{Pt}-\mathrm{TiO}_{2}$ catalyst (phenol pollutant).

The result obtained for the corrugated and finned reactors imply that the system does not exhibit mass transfer limitations for these configurations at this initial concentration $(20 \mathrm{ppm})$, and that the rate of degradation is dominated by the rate of the oxidation reaction, and not the rate of transfer of the pollutants to the catalyst surface. This is a significant advantage of the corrugated drum reactors, and it is believed that the improved mass transfer properties of the systems are due to the increased

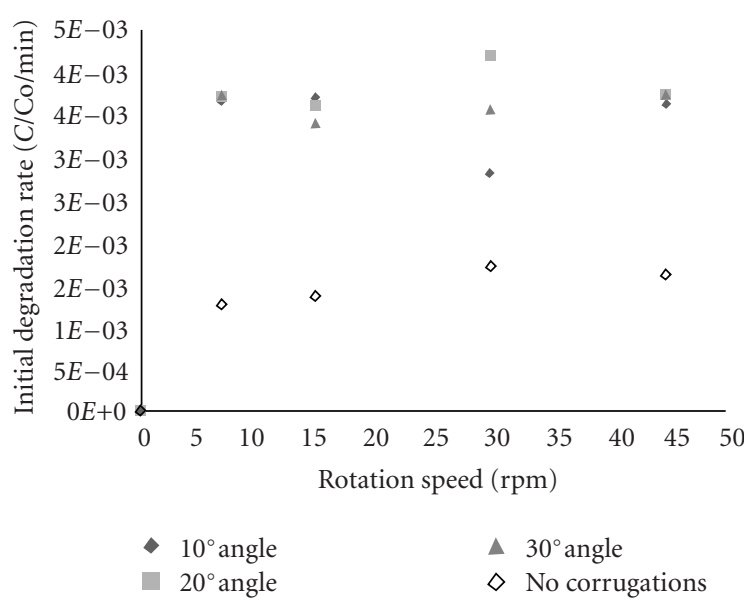

FIGURE 6: Effect of varying rotational speed on initial degradation rate for corrugated drums.

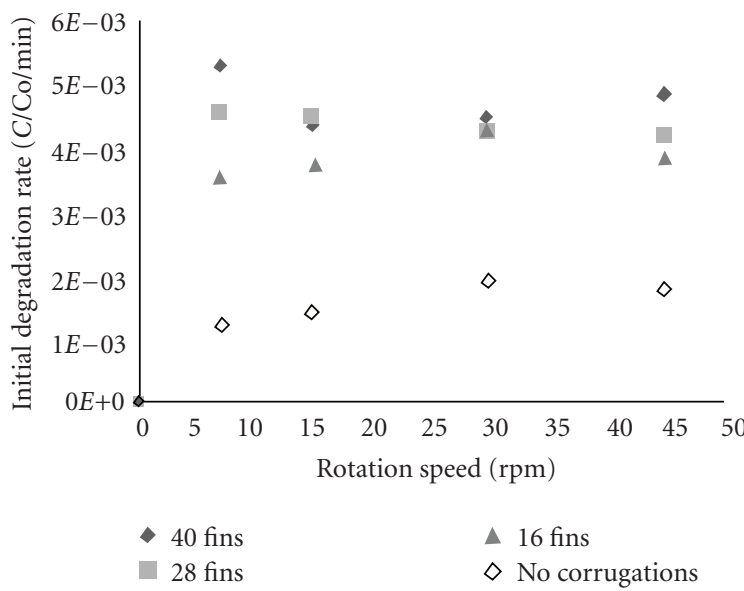

FIGURE 7: Effect of varying rotational speed on initial degradation rate for finned drums.

agitation and turbulence caused by the corrugation profiles and rotation. Additionally, the formation of bubbles on the surface of the finned and corrugated reactors also facilitates mass transfer of the pollutant, and it was visually observed that the formation of such bubbles increased as the number of fins or corrugations increased.

3.4. Effect of Initial Pollutant Concentration. The effect of initial phenol concentration at different rotational speeds using the 28 fin drum was conducted for initial concentrations ranging from $5 \mathrm{ppm}$ to $40 \mathrm{ppm}$, and the results are shown in Figure 8. At low initial concentrations (5-20 ppm), there is an increase in degradation rate with increasing initial concentration, but at higher concentrations (20$40 \mathrm{ppm}$ ), there is no further improvement in the degradation rate with increasing initial concentration. It can also be observed that there is a dependence of reaction rate on rotational speed at $5 \mathrm{ppm}$; the degradation rates at 30 and $45 \mathrm{rpm}$ are $76 \%$ higher than those at 7 and $15 \mathrm{rpm}$. The dependence of degradation rate on the rotational speed at 


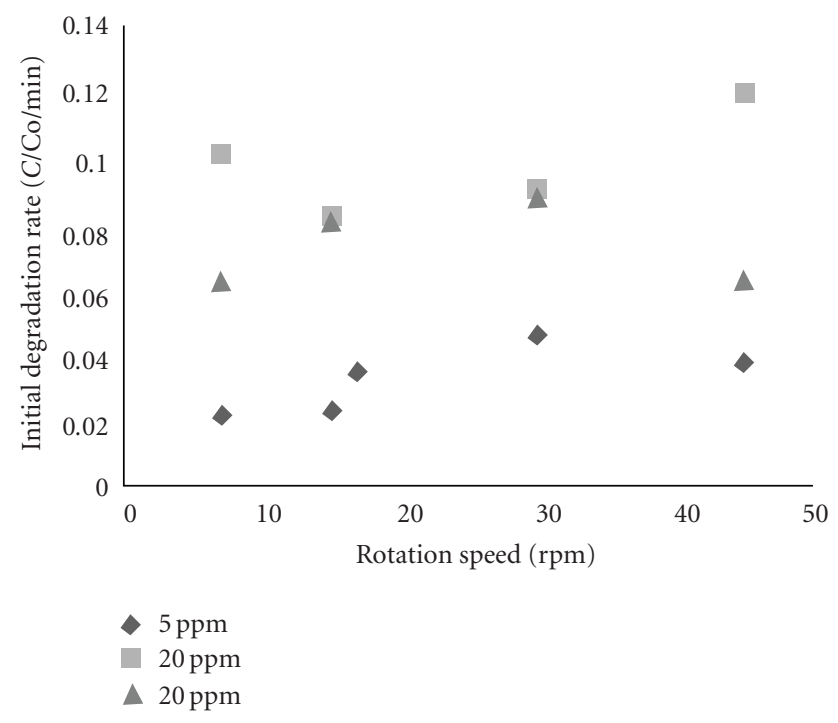

FIGURE 8: Effect of initial concentration on degradation rate for 28 fin drum.

this initial concentration and the increase in degradation rate between the $5 \mathrm{ppm}$ and $20 \mathrm{ppm}$ trials indicate that at lower concentrations ( $5 \mathrm{ppm})$, the reaction rate is limited by the ability to transfer reactants to the catalyst surface (masstransfer limitation). Conversely, at higher concentrations $(20-40 \mathrm{ppm})$, the reaction rate is limited by the kinetics rather than mass transfer.

3.5. Effect of Illumination Profile. The effect of illumination intensity on the phenol degradation was considered by conducting the experiment under nonmass transfer limited conditions using the 28 fin drum and changing the number of lights used. The degradation rate was found to increase with increasing light intensity and no critical intensity was reached within the limits of the reaction apparatus (Figure 9). An increase in the number of lamps used in the system from one to two was accompanied by an increase in degradation rate by $19 \%$. Similarly, increasing the number of lamps used from two to three increased the degradation rate by about $45 \%$. This is consistent with the trends found in the literature for the influence of light intensity on reaction rate below a critical value [41].

3.6. Effect Intermediate Residuals. The photocatalytic mineralization of phenol occurs in a series of elementary steps [3], and, according to a reaction mechanism study by Sobczyński et al. [42], the main reaction intermediates formed are catechol, resorcinol, hydroquinone, and benzoquinone, with hydroquinone making the largest contribution to the total organic carbon in the system. To quantify the presence of these reaction intermediates in the current photocatalytic system, samples were analyzed using HPLC as well as with a spectrophotometer. The results of the HPLC analysis and the spectrophotometric analysis for a single trial (40 fin drum, $15 \mathrm{rpm}$ ) are given in Figure 10.

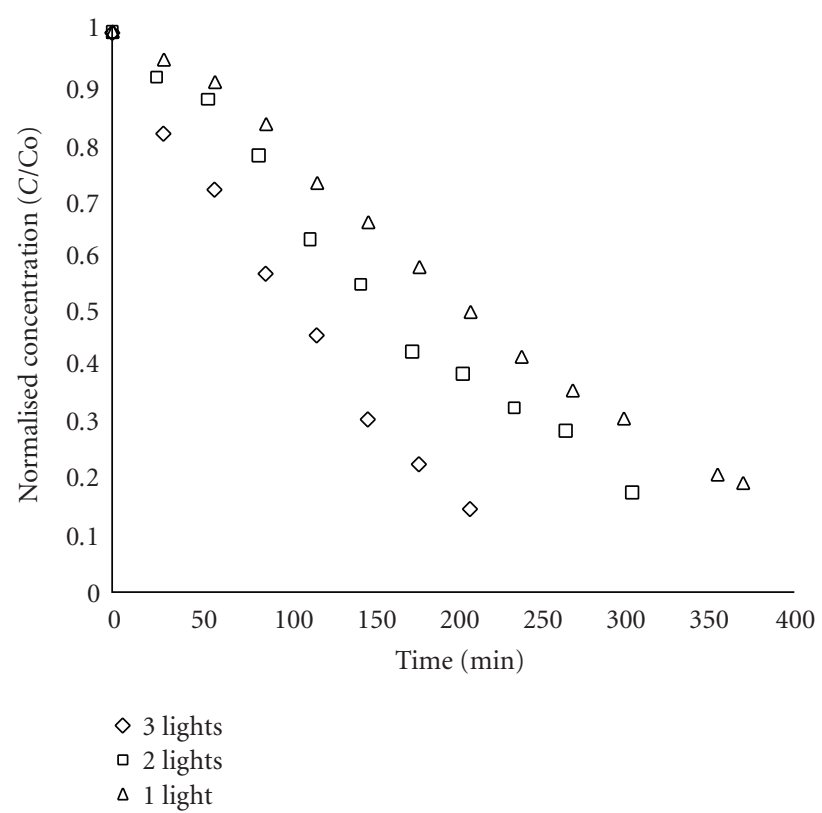

FIGURE 9: Effect of illumination profile on phenol degradation (28 fin drum).

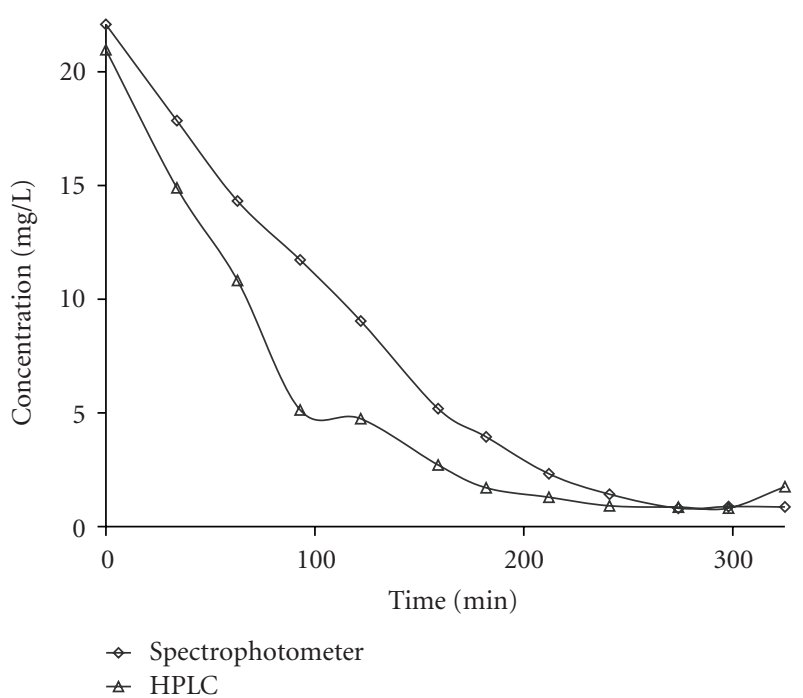

FIGURE 10: Comparison of phenol concentration as determined by spectrophotometry analysis and HPLC (40 fin drum).

From the analysis, the HPLC concentration of phenol is lower than that of the spectrophotometric determination in all cases. This indicates the presence of UV-absorbing reaction intermediates within the system. However, a similar degradation trend for phenol is observed in both curves, indicating that these intermediates do not greatly interfere with the experimental data.

3.7. Reaction Kinetics. A Langmuir-Hinshelwood kinetic analysis was used to describe the photocatalytic decomposition of organic compounds [43]. When the solvent and 
TABLE 2: Initial degradation rate and Langmuir-Hinshelwood kinetic constants.

\begin{tabular}{lccc}
\hline Drum configuration & Surface area $\left(\mathrm{cm}^{2}\right)$ & $\begin{array}{c}\text { Degradation rate } \\
(\mathrm{C} / \mathrm{Co} / \mathrm{min})\end{array}$ & $\begin{array}{c}\text { Overall reaction rate } \\
\text { constant }\left(k_{r}\right)\end{array}$ \\
\hline No corrugations & 405 & 0.0014 & 0.046 \\
16 Fins & 1704 & 0.0038 & 0.13 \\
28 Fins & 2679 & 0.0045 & 0.15 \\
40 Fins & 3653 & 0.0044 & 0.16 \\
$30^{\circ}$ Angle & 1164 & 0.0036 & 0.17 \\
$20^{\circ}$ Angle & 1402 & 0.0037 & 0.12 \\
$10^{\circ}$ Angle & 2411 & 0.0034 & 0.12 \\
\hline
\end{tabular}

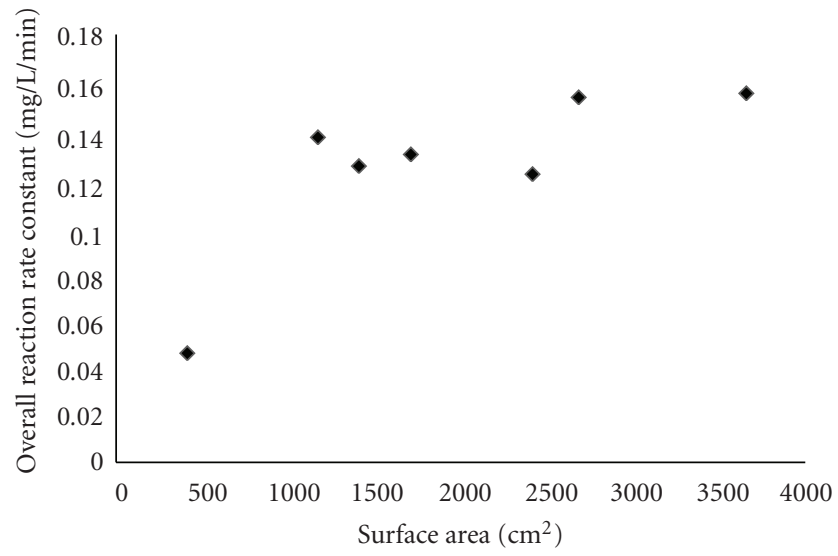

Figure 11: L-H overall reaction rate constants for seven drum configurations $(\mathrm{Co}=20 \mathrm{ppm}, 15 \mathrm{rpm})$.

reactant do not compete for reaction sites, the model can be expressed using

$$
\text { Rate }=-\frac{d C}{d t}=\frac{k_{r} K C}{1+K C} .
$$

The average adsorption coefficient found from the experimental data for all of the drums $(15 \mathrm{rpm}, \mathrm{Co}=20 \mathrm{ppm})$ was $K=0.12 \mathrm{~L} / \mathrm{mg}$. The overall reaction rate constant $\left(k_{r}\right)$ was then found, and the results obtained ranged from $0.046 \mathrm{mg} / \mathrm{L} / \mathrm{min}$ for the annular drum to $0.16 \mathrm{mg} / \mathrm{L} / \mathrm{min}$ for the 40 fin drum. The overall reaction rate constants are plotted as a function of surface area in Figure 11. From the results, the general trend is observed that increasing the surface area does have the effect of increasing the overall reaction rate constant using the LH model, and this advantage is especially realized when comparing the annular drum to the corrugated and finned drums. This implies that better treatment capacities can be realized using drums with higher surface areas.

A summary of the initial degradation rate and LangmuirHinshelwood kinetics is given in Table 2 .

3.8. Photonic Efficiency. The apparent photonic efficiency can be used to describe the number of reactant molecules transformed divided by the number of photons, at a given wavelength, incident inside the reactor cell [44]. This value evaluated is lower than the quantum yield, since it takes into account scattered radiation from the surface of the catalyst.

Since the concentration is not linear with time, the photonic efficiency is variable. However, in the initial stage of reaction (at $t=20 \mathrm{~min}$ ), the concentration varies approximately linearly with time. This data point was used to calculate photonic efficiency. The Planck relationship was used to calculate the number of incident photons.

Because the radiation profile was not modelled or measured within this work, an adaptation of the apparent photonic efficiency was used to compare the effectiveness of light utilization among the seven drums studied at the same reaction conditions. In this evaluation, the total photonic light input (from the lamps) was calculated and used directly in (3). This evaluation and the numbers obtained should be considered for comparative purposes only, as it is not, strictly, an "apparent photonic efficiency". It should be noted that, in reported studies using a rotating disc reactor, the photon flow rate onto the RDR was $11 \%$ greater than that on an annular drum due to the reflected photon capture from the angled teeth [7]. It is expected that, using a proper evaluation of apparent photonic efficiency for each of the corrugated drums in this study, the photon flow rate captured from reflection would decrease the calculated apparent photonic efficiency slightly when compared to the annular drum. The obtained results from this study are given in Figure 12.

It can be seen that the apparent photonic efficiency increases with increasing reactor surface area, which is consistent with the results obtained by Zhang et al. [7]. For the corrugations and finned drums, the increase is approximately linear. From the calculated slopes, it can be seen that the apparent photonic efficiency increases at a faster rate than for the finned drums. This being said, there is a practical limit as to the number of corrugations which can physically fit on a drum of fixed diameter. While the efficiencies calculated cannot be compared with literature values quantitatively, the conclusion can be drawn that the finned and corrugated drums do outperform the annular drum due to their increase surface area, and that the corrugated drums make better use of the light input into the system. As a result, increasing the surface area through the use of corrugations is an effective way of distributing a limited amount of light to perform the same degradation. 


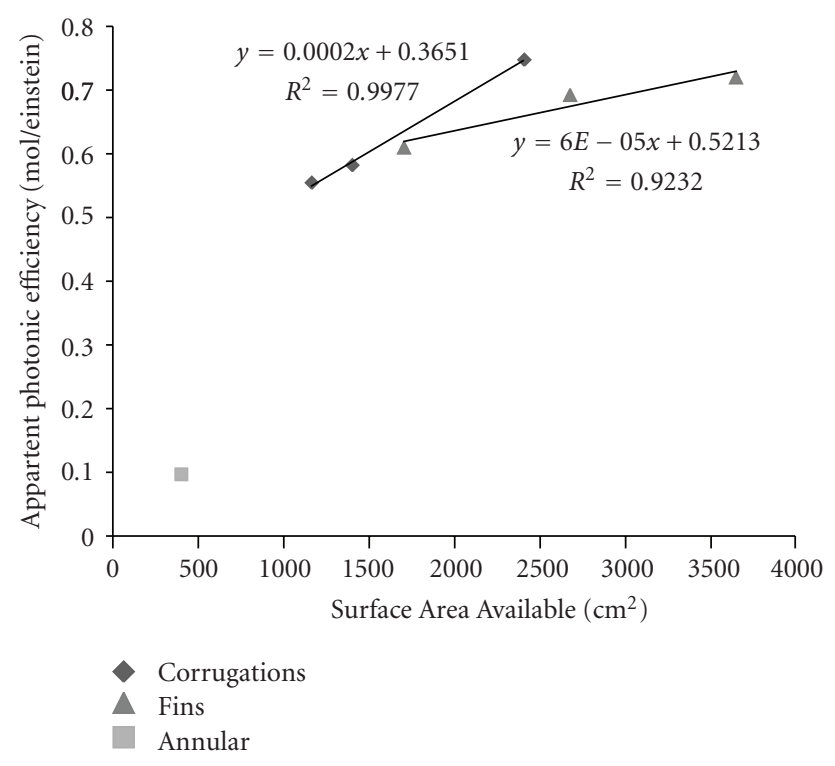

Figure 12: Apparent photonic efficiency for the seven drum configurations ( $\mathrm{Co}=15 \mathrm{ppm}, 15 \mathrm{rpm})$.

TABLE 3: EE/O for seven drum configurations.

\begin{tabular}{lc}
\hline Drum configuration & $\mathrm{EE} / \mathrm{O}\left(\mathrm{kWh} / \mathrm{m}^{3}\right)$ \\
\hline No corrugations (annular) & 1860 \\
16 Fins & 420 \\
28 Fins & 550 \\
40 Fins & 380 \\
$30^{\circ}$ Angle & 460 \\
$20^{\circ}$ Angle & 520 \\
$10^{\circ}$ Angle & 530 \\
\hline
\end{tabular}

3.9. Energy Efficiency. The energy efficiency for processes in which light is an input can be calculated easily using electrical energy per order (EE/O) [6]. This value is defined as the electrical energy ( $\mathrm{kWh}$ ) required to mineralize the pollutant in $1 \mathrm{~m}^{3}$ of contaminated water by one order of magnitude. The EE/O is given by (3) and generally decreases with increasingly energy-efficient systems

$$
\mathrm{EE} / \mathrm{O}=\frac{P t}{V \log \left(\mathrm{Co} / C_{f}\right)} .
$$

This evaluation of energy efficiency is unbiased for reactions following first-order kinetics; however, for other types of kinetics, the EE/O is a function of initial pollutant concentration and can only be used for rough estimation purposes [6]. The calculated $\mathrm{EE} / \mathrm{O}$ values for the seven different drums studied at the same reaction conditions $(15 \mathrm{rpm}, \mathrm{Co}=$ $15 \mathrm{ppm}$ ) are given in Table 3.

From the obtained results, the corrugated and finned drums have approximately similar energy efficiencies and are all much more energy efficient than the annular drum. The energy efficiency of the corrugated and finned drums is up to
$490 \%$ better than that of the annular drum. It is expected that the improved energy efficiency is due to the photon absorption and reflection characteristics of the corrugated and finned drums. The reason for the similarity between the values obtained between the fins and corrugations could be due to the close range of fin number and corrugation angles studied. EE/O values obtained from the corrugated and finned profiles is still greater than that reported using a slurry system $\left(106 \mathrm{kWh} / \mathrm{m}^{3}\right.$, however, the initial concentration used in the reported study was $94 \mathrm{ppm}$ [3], so direct comparison should be approached with caution).

\section{Conclusions}

The photoreactor system developed shows promising results for the degradation of the phenol pollutant in wastewaters. The drum configuration design increases the catalyst immobilization surface area and promotes reactant loading at the reaction sites. The introduction of rotation improves agitation, allowing reactant transfer to the illuminated drum surface and incorporating periodic illumination effects. The following conclusions were reached.

(i) The additions of corrugations and fins significantly improved the performance of the reactor for the degradation of phenol, and there was up to $200 \%$ improvement.

(ii) The corrugated and finned drums did not show a critical rotation speed from 0 to $45 \mathrm{rpm}$, indicating that there is excellent mass transfer in the system.

(iii) The use of delivered photons was greater for the corrugated than finned drums, and increasing the surface area through the use of corrugations is an effective way of improving the reactor performance for a fixed amount of light.

(iv) The energy efficiency (EE/O) for the corrugated and finned drums were in the range of $380-550 \mathrm{KWh} / \mathrm{m}^{3}$ and were up to $490 \%$ times energy efficient than the drum reactor with no corrugations.

The developed design is also advantageous because it has the potential to be rotated using the hydraulic force of falling water, much like an ancient water wheel, while photocatalytically degrading organic species contained within the aqueous stream and could potentially be adopted to solar illumination in order to maximize the energy efficiency. Alternatively, the reactors could be used in series in a channel of flowing water which could drive the rotations. As such, the versatility in design holds great potential for future application. Further analysis should be done on the radiation profile and modeling of performance in order to optimize the corrugation angles. A wider range of degrees of corrugation and number of fins should also be studied to quantify the differences between the drums in a more statistically significant way. Experimental validation of this system for use with visible light sources should also be considered. 


\section{Nomenclature}

$C(t)$ : Concentration of phenol at time $t(\mathrm{mg} / \mathrm{L})$

Co: Initial concentration of phenol $(\mathrm{mg} / \mathrm{L})$

$C_{f}$ : Concentration of phenol at end of experimental time $(\mathrm{mg} / \mathrm{L})$

$\mathrm{C}_{0_{2}}$ : Concentration of oxygen dissolved in water $\left(\mathrm{g} / \mathrm{m}^{3}\right)$

D: Diffusion coefficient of oxygen in water $\left(1.54 \times 10^{-5} \mathrm{~cm}^{2} / \mathrm{s}\right.$ at $\left.10^{\circ} \mathrm{C}\right)$

$K$ : Adsorption coefficient in Langmuir-Hinshelwood expression ( $\mathrm{L} / \mathrm{mg})$

$k_{r}$ : Overall reaction rate constant $(\mathrm{mg} / \mathrm{L} \mathrm{min})$

$\mathrm{N}_{\mathrm{O}_{2}}$ : Diffusive flux of oxygen in the water film $\left(\mathrm{g} / \mathrm{m}^{2} \cdot \mathrm{s}\right)$

$P: \quad$ Input power $(\mathrm{W})$

$R: \quad$ Coordinate in the radial direction of rotation for disc/drum

$t$ : $\quad$ Experimental time $(h)$

$V$ : Volume of solution in tank $\left(\mathrm{m}^{3}\right)$.

\section{Acknowledgments}

Financial support was provided by the Natural Sciences and Engineering Research Council of Canada. Sarah Meunier (Mercer) and Joanne Gamage were the holders of graduate scholarships from the Natural Sciences and Engineering Research Council of Canada during this study.

\section{References}

[1] D. F. Ollis, "Photocatalytic purification and remediation of contaminated air and water," Comptes Rendus de l'Academie des Sciences-Series IIc: Chemistry, vol. 3, no. 6, pp. 405-411, 2000.

[2] R. F. P. Nogueira and W. F. Jardim, "TiO-fixed-bed reactor for water decontamination using solar light," Solar Energy, vol. 56, no. 5, pp. 471-477, 1996.

[3] K. Okamoto, Y. Yamamoto, M. Tanaka, and A. Itaya, "Heterogeneous photocatalytic decomposition of phenol over $\mathrm{TiO}_{2}$ powder," Bulletin of the Chemical Society of Japan, vol. 58, pp. 2015-2022, 1985.

[4] V. P. Vinod and T. S. Anirudhan, "Photocatalytic degradation for environmental applications-a review," Journal of Chemical Technology and Biotechnology, vol. 77, no. 1, pp. 102-116, 2002.

[5] A. K. Ray, "Photocatalytic reactor configurations for water purification: experimentation and modeling," in Advanced in Chemical Engineering, $\mathrm{H}$. de Lasa and b. S. Rosales, Eds., vol. 36, pp. 145-183, Elsevier Science, Amsterdam, The Netherlands, 2009.

[6] Z. Zhang, W. A. Anderson, and M. Moo-Young, "Experimental analysis of a corrugated plate photocatalytic reactor," Chemical Engineering Journal, vol. 99, no. 2, pp. 145-152, 2004.

[7] L. Zhang, W. A. Anderson, and Z. Zhang, "Development and modeling of a rotating disc photocatalytic reactor for wastewater treatment," Chemical Engineering Journal, vol. 121, no. 2-3, pp. 125-134, 2006.
[8] A. E. Cassano, C. A. Martín, R. J. Brandi, and O. M. Alfano, "Photoreactor analysis and design: Fundamentals and applications," Industrial and Engineering Chemistry Research, vol. 34, no. 7, pp. 2155-2201, 1995.

[9] L. Jakob, E. Oliveros, O. Legrini, and A. M. Braun, " $\mathrm{TiO}_{2}$ photocatalytic treatment of water. Reactor design and optimization experiments," in Photocatalytic Purification and Treatment of Water and Air, D. F. Ollis and H. Al-Ekabi, Eds., pp. 511-532, Elsevier Science, Amsterdam, The Netherlands, 1993.

[10] O. Legrini, E. Oliveros, and A. M. Braun, "Photochemical processes for water treatment," Chemical Reviews, vol. 93, no. 2, pp. 671-698, 1993.

[11] P. L. Yue, "Modelling, scale-up and design of multi-phasic photoreactors," in Photocatalytic Purification and Treatment of Water and Air, D. F. Ollis and H. Al-Ekabi, Eds., pp. 495-510, Elsevier Science, Amsterdam, The Netherlands, 1993.

[12] A. Sclafani, A. Brucato, and L. Rizzuti, "Mass transfer limitations in a packed bed photoreactor used for phenol removal," in Photocatalytic Purification and Treatment of Water and Air, D. F. Ollis and H. Al-Ekabi, Eds., pp. 495-510, Elsevier Science, Amsterdam, The Netherlands, 1993.

[13] J. G. Sczechowski, C. A. Koval, and R. D. Noble, "A Taylor vortex reactor for heterogeneous photocatalysis," Chemical Engineering Science, vol. 50, no. 20, pp. 3163-3173, 1995.

[14] A. Haarstrick, O. M. Kut, and E. Heinzle, "TiO -assisted degradation of environmentally relevant organic compounds in wastewater using a novel fluidized bed photoreactor," Environmental Science and Technology, vol. 30, no. 3, pp. 817$824,1996$.

[15] D. F. Ollis, E. Pelizzetti, and N. Serpone, "Heterogeneous photocatalysis in the environment: application to water purification," in Photocatalysis: Fundamentals and Applications, N. Serpone and E. Pelizzetti, Eds., pp. 603-637, John Wiley \& Sons, New York, NY, USA, 1989.

[16] N. J. Peill and M. R. Hoffmann, "Development and optimization of a $\mathrm{TiO}_{2}$-coated fiber-optic cable reactor: Photocatalytic degradation of 4-chlorophenol," Environmental Science and Technology, vol. 29, no. 12, pp. 2974-2981, 1995.

[17] N. J. Peill and M. R. Hoffmann, "Chemical and physical characterization of a $\mathrm{TiO}_{2}$-coated fiber optic cable reactor," Environmental Science and Technology, vol. 30, no. 9, pp. 28062812, 1996.

[18] N. J. Peill and M. R. Hoffmann, "Mathematical model of a photocatalytic fiber-optic cable reactor for heterogeneous photocatalysis," Environmental Science and Technology, vol. 32, no. 3, pp. 398-404, 1998.

[19] H. C. Yatmaz, C. R. Howarth, and C. Wallis, "Photocatalysis of organic effluents in a falling film reactor," in Photocatalytic Purification and Treatment of Water and Air, D. F. Ollis and H. Al-Ekabi, Eds., pp. 795-800, Elsevier Science, Amsterdam, The Netherlands, 1993.

[20] D. Bockelmann, R. Goslich, D. Weichgrebe, and D. Bahnemann, "Solar detoxification of polluted water: comparing the efficiencies of a parabolic through reactor and a novel thin-film fixed-bed reactor," in Photocatalytic Purification and Treatment of Water and Air, D. F. Ollis and H. Al-Ekabi, Eds., pp. 771-776, Elsevier Science, Amsterdam, The Netherlands, 1993.

[21] A. K. Ray and A. A. C. M. Beenackers, "Novel swirl-flow reactor for kinetic studies of semiconductor photocatalysis," AIChE Journal, vol. 43, no. 10, pp. 2571-2578, 1997. 
[22] R. A. Damodar and S. J. You, "Performance of an integrated membrane photocatalytic reactor for the removal of Reactive Black 5," Separation and Purification Technology, vol. 71, no. 1, pp. 44-49, 2010.

[23] P. Du, J. T. Carneiro, J. A. Moulijn, and G. Mul, "A novel photocatalytic monolith reactor for multiphase heterogeneous photocatalysis," Applied Catalysis A: General, vol. 334, no. 1-2, pp. 119-128, 2008.

[24] V. Augugliaro, M. Litter, L. Palmisano, and J. Soria, "The combination of heterogeneous photocatalysis with chemical and physical operations: A tool for improving the photoprocess performance," Journal of Photochemistry and Photobiology C: Photochemistry Reviews, vol. 7, no. 4, pp. 127-144, 2006.

[25] J. Blanco-Galvez, P. Fernández-Ibáñez, and S. MalatoRodríguez, "Solar photo catalytic detoxification and disinfection of water: Recent overview," Transactions of the ASME, vol. 129, no. 1, pp. 4-15, 2007.

[26] D. Bahnemann, "Photocatalytic water treatment: Solar energy applications," Solar Energy, vol. 77, no. 5, pp. 445-459, 2004.

[27] R. Goslich, R. Dillert, and D. Bahnemann, "Solar water treatment: Principles and reactors," Water Science and Technology, vol. 35, no. 4, pp. 137-148, 1997.

[28] D. Y. Goswami, "A review of engineering developments of aqueous phase solar photocatalytic detoxification and disinfection processes," Transactions of the ASME, vol. 119, no. 2, pp. 101-107, 1997.

[29] S. M. Rodríguez, J. B. Gálvez, M. I. M. Rubio et al., "Engineering of solar photocatalytic collectors," Solar Energy, vol. 77, no. 5, pp. 513-524, 2004.

[30] R. J. Braham and A. T. Harris, "Review of major design and scale-up considerations for solar photocatalytic reactors," Industrial and Engineering Chemistry Research, vol. 48, no. 19, pp. 8890-8905, 2009.

[31] Z. Zhang, W. A. Anderson, and M. Moo-Young, "Rigorous modeling of UV absorption by $\mathrm{TiO}_{2}$ films in a photocatalytic reactor," AIChE Journal, vol. 46, no. 7, pp. 1461-1467, 2000.

[32] Z. Zhang, W. A. Anderson, and M. Moo-Young, "Modeling of corrugated plate photocatalytic reactors and experimental validation," Chemical Engineering Science, vol. 58, no. 3-6, pp. 911-914, 2003.

[33] D. D. Dionysiou, A. P. Khodadoust, A. M. Kern, M. T. Suidan, I. Baudin, and J. M. Laîné, "Continuous-mode photocatalytic degradation of chlorinated phenols and pesticides in water using a bench-scale $\mathrm{TiO}_{2} \mathrm{O}$ rotating disk reactor," Applied Catalysis B: Environmental, vol. 24, no. 3-4, pp. 139-155, 2000.

[34] N. A. Hamill, L. R. Weatherley, and C. Hardacre, "Use of a batch rotating photocatalytic contactor for the degradation of organic pollutants in wastewater," Applied Catalysis B: Environmental, vol. 30, no. 1-2, pp. 49-60, 2001.

[35] W. Tanthapanichakoon, T. Charinpanitkul, T. Yamamoto, N. Sano, and N. Thongprachan, "A novel rotary drum filtering photoreactor for wastewater treatment using titanium dioxide nanoparticles," in Proceedings of the 2nd IEEE International Conference on Nano/Micro Engineered and Molecular Systems (NEMS '07), pp. 438-442, Bangkok, Thailand, January 2007.

[36] L. Zhang, T. Kanki, N. Sano, and A. Toyoda, "Photocatalytic degradation of organic compounds in Aqueous solution by a $\mathrm{TiO}_{2}$-coated rotating-drum reactor using solar light," Solar Energy, vol. 70, no. 4, pp. 331-337, 2001.

[37] J. G. Sczechowski, C. A. Koval, and R. D. Noble, "Evidence of critical illumination and dark recovery times for increasing the photoefficiency of aqueous heterogeneous photocatalysis," Journal of Photochemistry and Photobiology, A: Chemistry, vol. 74, no. 2-3, pp. 273-278, 1993.
[38] H. Shang, Z. Zhang, and W. A. Anderson, "Nonuniform radiation modeling of a corrugated plate photocatalytic reactor," AIChE Journal, vol. 51, no. 7, pp. 2024-2033, 2005.

[39] D. D. Dionysiou, M. T. Suidan, I. Baudin, and J. M. Laîné, "Oxidation of organic contaminants in a rotating disk photocatalytic reactor: reaction kinetics in the liquid phase and the role of mass transfer based on the dimensionless Damköhler number," Applied Catalysis B: Environmental, vol. 38, no. 1, pp. $1-16,2002$.

[40] D. D. Dionysiou, A. P. Khodadoust, A. M. Kern, M. T. Suidan, I. Baudin, and J. M. Laîné, "Continuous-mode photocatalytic degradation of chlorinated phenols and pesticides in water using a bench-scale $\mathrm{TiO}_{2}$ rotating disk reactor," Applied Catalysis B: Environmental, vol. 24, no. 3-4, pp. 139-155, 2000.

[41] D. F. Ollis, E. Pelizzetti, and N. Serpone, "Photocatalyzed destruction of water contaminants," Environmental Science and Technology, vol. 25, no. 9, pp. 1522-1529, 1991.

[42] A. Sobczyński, L. Duczmal, and W. Zmudziński, "Phenol destruction by photocatalysis on TiO: an attempt to solve the reaction mechanism," Journal of Molecular Catalysis A: Chemical, vol. 213, no. 2, pp. 225-230, 2004.

[43] H. Al-Ekabi and N. Serpone, "Kinetic studies in heterogeneous photocatalysis. 1. Photocatalytic degradation of chlorinated phenols in aerated aqueous solutions over $\mathrm{TiO}_{2}$ supported on a glass matrix," Journal of Physical Chemistry, vol. 92, no. 20, pp. 5726-5731, 1988.

[44] N. Serpone, "Relative photonic efficiencies and quantum yields in heterogeneous photocatalysis," Journal of Photochemistry and Photobiology A: Chemistry, vol. 104, no. 1-3, pp. 112, 1997. 


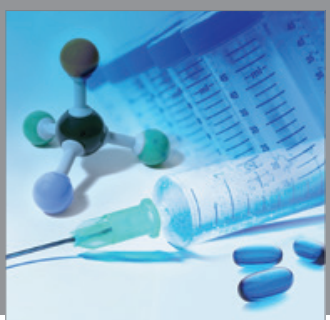

International Journal of

Medicinal Chemistry

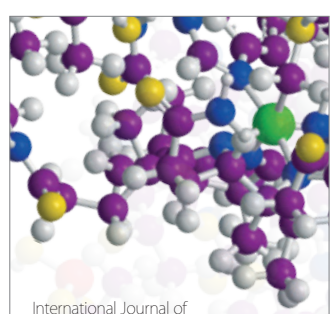

Carbohydrate Chemistry

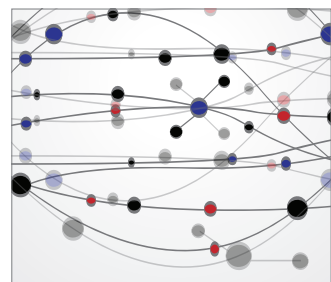

The Scientific World Journal
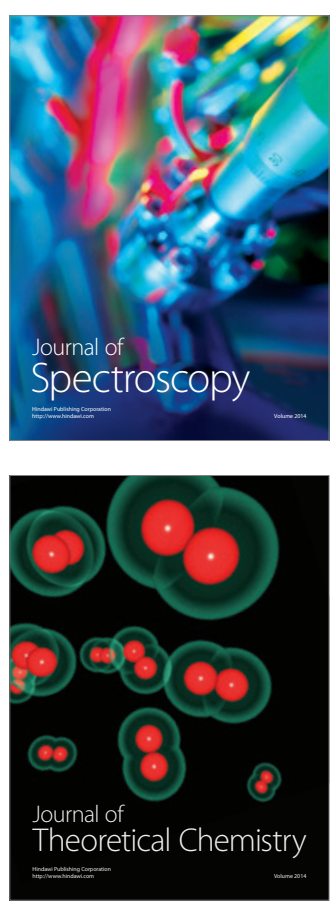
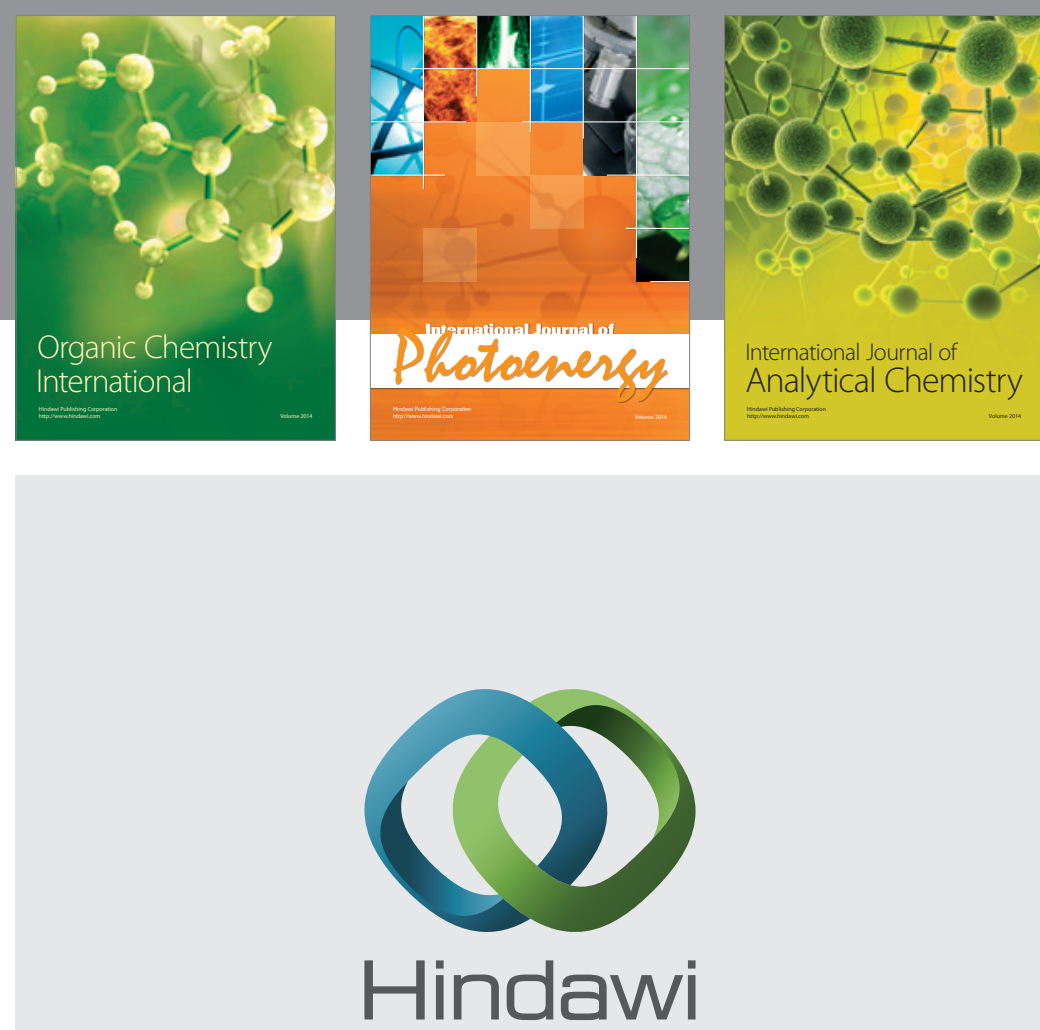

Submit your manuscripts at

http://www.hindawi.com
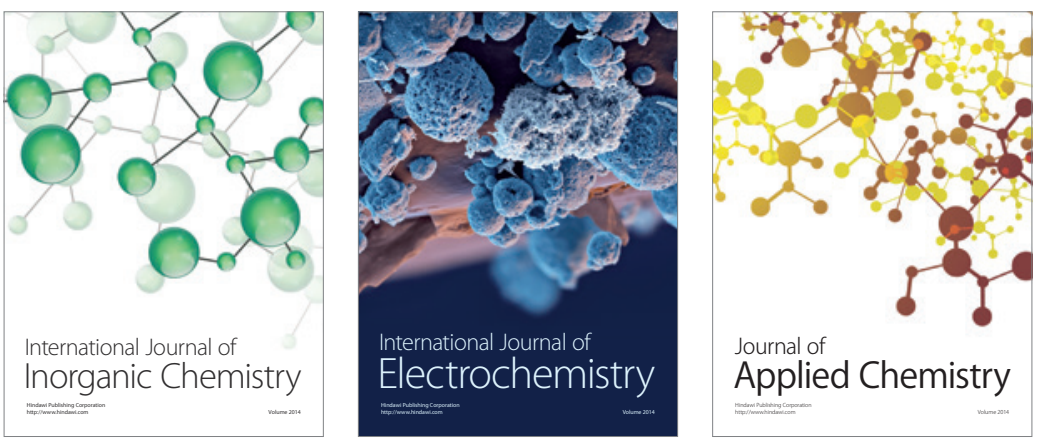

Journal of

Applied Chemistry
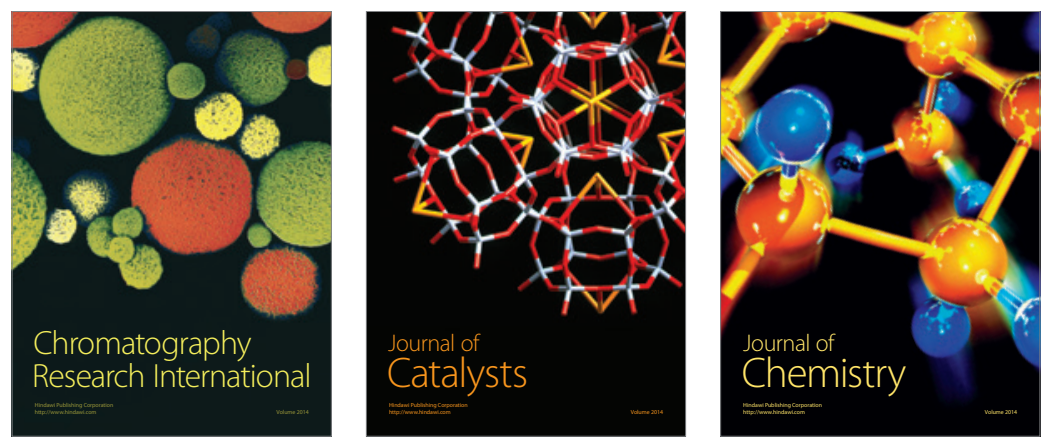
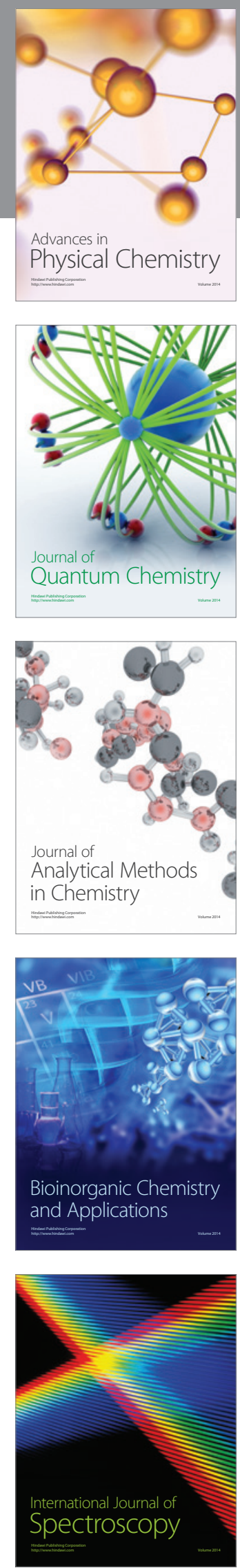